\title{
La comunicación organizacional: Un factor para elevar la productividad en las organizaciones
}

\section{Organizational communication: A factor to increase productivity in organizations}

\author{
Víctor M. Piedra-Mayorga ${ }^{a}$, Rafael Granillo Macías ${ }^{b}$, Renato Ezequiel González Romero ${ }^{c}$, \\ Raúl Rodríguez-Moreno ${ }^{d}$, Miguel A. Vázquez-Alamilla ${ }^{e}$
}

\begin{abstract}
:
To increase the effectiveness of the human team, the worker must feel motivated and integrated within their organization. One factor to achieve productivity is to keep all members well informed, which includes knowing the company, its mission, philosophy, values, or strategies, you must feel part of the organization and be willing to give everything of yourself to her, this reduces uncertainty and prevents or avoids rumors, allows to transmit corporate messages. In this research, factors that affect communication aspects in organizations are determined, highlighting that the relationship between employees, management and the different departments of the company is vital to establish an effective line towards productivity.
\end{abstract}

\section{Keywords:}

Organizational communication, business productivity, types of communication

\section{Resumen:}

Para aumentar la eficacia del equipo humano, el trabajador debe sentirse motivado e integrado dentro de su organización. Un factor para lograr la productividad es mantener bien informado a todos los integrantes, donde se incluye el conoce la compañía, su misión, filosofía, valores, o estrategias, debe sentirse parte en la organización y estar dispuestos a dar todo de sí mismo para ella, esto reduce la incertidumbre y previene o evita los rumores, permite transmitir mensajes corporativos. En esta investigación se determinan de factores que inciden en los aspectos de la comunicación en las organizaciones, destacando que la relación entre empleados, la dirección y los diferentes departamentos de la empresa es vital para establecer una línea eficaz hacia la productividad.

\section{Palabras Clave:}

Comunicación organizacional, productividad empresarial, tipos de comunicación

\footnotetext{
Autor de Correspondencia, Universidad Autónoma del Estado de Hidalgo, https://orcid.org/0000-0002-1213-7632, Email: piedrinix@gmail.com

b Universidad Autónoma del Estado de Hidalgo, Escuela Superior de Ciudad Sahagún, https://orcid.org/0000-0002-1015-667X, Email: rafaelgm@uaeh.edu.mx

c Universidad Autónoma de Tlaxcala, Unidad Académica Multidisciplinaria Campus Calpulalpan, https://orcid.org/0000-0001-7916-5585, Email: ezzek669@hotmail.com

d Universidad Autónoma del Estado de Hidalgo, https://orcid.org /0000-0001-8533-8024, Email: raromo@ hotmail.com

e Universidad Autónoma del Estado de Hidalgo, https://orcid.org/0000-0001-5349-7522, Email: m_vazquez_alamilla@hotmail.com
} 


\section{Introducción}

El conocimiento se genera principalmente en la parte baja de la pirámide jerárquica, por lo que este tipo de comunicación resulta fundamental para el desarrollo del negocio, el reto entonces es evolucionar hacia procesos de escucha y acompañamiento a cada uno de los trabajadores, la pandemia del Covid-19 evolucionó e impactó en el estilo de vida, así como en lo familia y trabajo, modifico la forma de comunicación en la organización y colaboradores sobrepasando las actividades y el exceso de comunicados. Con la gran diversificación en los canales de comunicación, se vuelve complejo poder saber cuáles son los más efectivos (Jiménez, 2007).

El objetivo de esta investigación fue analizar y determinar los efectos de la comunicación organizacional como factor para elevar la productividad. La presente investigación es de tipo descriptivo y analítico, porque solo describe 0 estima parámetros, es analítico porque establece asociaciones entre factores y es de nivel descriptivo relacional porque solo se demuestran la dependencia entre las dimensiones de estudio.

El auge de las redes sociales, el uso del celular y movilidad de los canales de comunicación se han multiplicado de forma acelerada, y muchas veces su función de estos medios de comunicación no tiene el uso adecuado. Se invierten muchas horas en recursos humanos y económicos sin tener mucho éxito para lograr una mejor comunicación y entendimiento, ya que lo que se necesita en muchos de los casos es saber escuchar y dar acompañamiento a los colaboradores o integrantes de la organización (Fandos, 2003). Actualmente se vive una sociedad híper comunicada con estrés y sobre estimulada, lo que deriva en un reto para ser más creativos y buscar distintas formas de comunicación con los colaboradores sin que sean intrusivas, pero a la vez que logren su objetivo, de ahí la importancia de generar ambientes y climas laborales sin formalismos donde se puedan abordar temas relevantes para los colaboradores. Es necesario como menciona Fandos (2003) generar espacios donde se escuche y actúe en consecuencia, permitiendo además tener canales de comunicación formales, como el correo electrónico o aplicaciones móviles. La comunicación se define como un proceso en doble sentido de intercambio de información con un propósito mediante el cual, usando símbolos, tics y otros medios, una persona transmite un mensaje a otra $u$ otras quienes deben ser capaces de entender dichos símbolos para dar una respuesta y alcanzar los objetivos establecidos en una empresa de acuerdo con su cultura. En la comunicación necesariamente debe transmitirse y recibir otra persona la información de lo contrario no existe esta. En el proceso de la comunicación, el propósito ayuda a compartir el significado de datos, ideas, actitudes, opiniones, para lograr acciones, comprensión, coordinación u otros. La comunicación puede ser oral, de cara a cara, escrita en medios impresos, símbolos, señales convencionales o virtuales utilizando plataformas digitales o dispositivos. En particular, la comunicación formal utiliza medios o canales por los que fluye información para una eficiente coordinación, y de manera informal cuando existen preferencias o insatisfacciones de los empleados. En el caso de medios virtuales (Figura 1), se participa en plataformas, blogs o grupal local o mundial (Hernández, 2015).

Figura 1. Cambios en el esquema de comunicación
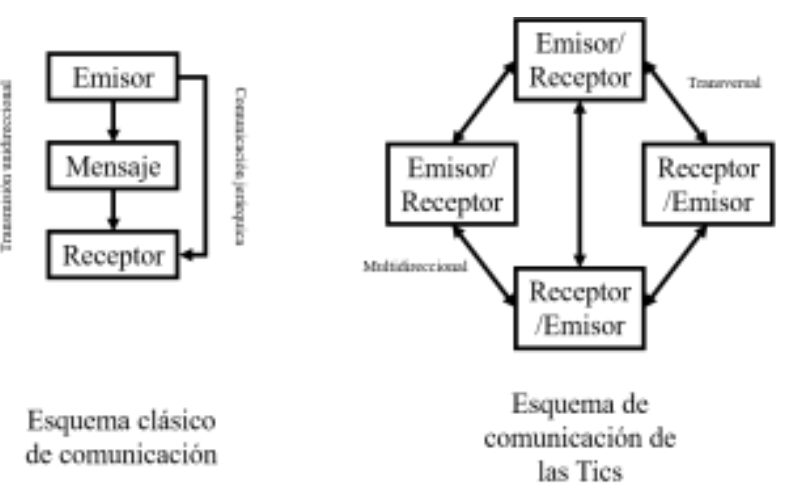

Fuente: Elaboración propia

La actividad administrativa requiere que la comunicación sea fluida y que permita guiar a quienes laboran en la empresa con el propósito de recibir y ofrecer instrucciones, supervisando, en el papel de jefes, subordinados o realizando determinadas funciones, ya que requieren comunicarse con otras personas. En muchos casos, las empresas ignoran que para ser más competitivas y enfrentarse con éxito al cambio del mercado deben motivar a su equipo, retener a los mejores y promover una verdadera cultura corporativa para que se sientan identificados y sean fieles a la organización. La comunicación interna se convierte en una herramienta estratégica para potenciar el sentimiento de pertenencia de los empleados con la empresa, permitiendo retener el talento (Fandos, 2003). Metafóricamente, la comunicación de la empresa se puede comparar con la circulación de la sangre en el cuerpo humano, donde las comunicaciones están sujeta a bajas y altas presiones (Lorente \&Jiménez, 2009); de esta manera, la comunicación fluida y adecuada en las empresas es importante por las siguientes razones:

- Ahorra recursos económicos.

- Hace más eficiente la administración de la empresa. 
- Mejora el proceso para la realización de las funciones administrativas.

- Desarrolla un mejor ambiente de trabajo.

- Fomenta las relaciones entre las personas.

- Ayuda al empleado a comprender la cultura organizacional de la empresa.

- Fortalece ideas, conocimientos y sentimientos.

- Logra que hablen y entiendan el mismo idioma todos los empleados, jefes y líderes.

- Mejora la actividad de la comunicación entre jefes y empleados, función a la que los primeros dedican mucho tiempo.

- Disminuyen las deficiencias por falta de inadecuada comunicación.

- La comunicación es más rápida, se puede visualizar con imágenes, sonidos.

- Se puede realizar en cualquier momento y desde cualquier lugar.

\section{Tipos de comunicación}

\section{Comunicación interna}

La comunicación interna (Figura 2) fomenta el equilibrio emocional en sus empleados por medio de la motivación, el compañerismo, la solidaridad y el compromiso. De igual manera la comunicación en sus diferentes tipos se complementan con una gestión de grupo que facilita el crecimiento personal y colectivo generando un rendimiento constante y regular que permite la obtención de los resultados propuestos, facilita los procesos que requiera la compañía a través de sus comunicados o boletines entre departamentos, haciendo aclaraciones sobre los cambios realizados de ser necesario, porque es positivo reorientar o reubicar a las personas en sus funciones y en sus cargos para maximizar su rendimiento y por consecuencia obtener mejores resultados empresariales.

Figura 2. Tipos de comunicación

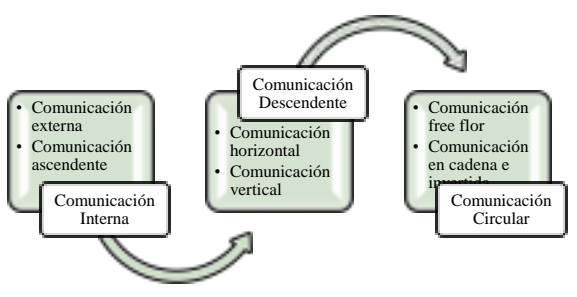

Fuente: Elaboración propia
Los clientes internos o trabajadores tienen influencia de los mensajes emitidos para mantener la empatía, la comunicación y espíritu solidario entre las distintas dependencias para obtener y mejorar los resultados. La comunicación interna es marcada por resultados inciertos en todos los niveles. De ahí que se esté convirtiendo en uno de los grandes retos profesionales del siglo XXI, donde todavía son pocas las entidades que desarrollan una adecuada política de comunicación interna que contribuya a implantar los cambios y lograr los objetivos corporativos y estratégicos de la compañía, se debe cuidar al cliente interno para dar respuesta satisfactoria a los clientes externos, no se debe empezar a construir la casa por el tejado (Marketing XXI, 2021).

Algunos elementos de un Plan de comunicación interna son:

1. Análisis: qué funciona y qué no.

2. Fijar los objetivos para eliminar reuniones improductivas, facilitar el acceso a información o mejorar procesos a través de la retroalimentación.

3. Establecer estrategias o plan de acción para mejorar las reuniones, intranet, correo electrónico o red social empresarial.

4. Medir resultados para comparar lo logrado con los objetivos a través del número de interacciones en la red social, número de reuniones, o tasa de apertura de boletines informativos

La comunicación interna persigue organizar y mejorar el intercambio de información entre áreas, esto impide a los departamentos o gerencias operar aisladas del resto de la organización, además, fomenta un ambiente de trabajo informado en el que los trabajadores saben quién los dirige y cómo, y la gerencia pueda a su vez conectarse con su equipo y saber de quiénes se trata, cuáles son sus fortalezas, debilidades y aspiraciones.

Generar una identidad corporativa, fomenta la idea de pertenencia entre los trabajadores e impulsa el trabajo en equipo, para promover la participación interna deben existir espacios para intercambiar ideas de forma física o virtual para dialogar o debatir, para compartir éxitos y retos, para brindar información importante y para innovar en estos campos (Jiménez, 2007). Con las Tics se forman equipos de programas informáticos y medios de comunicación para almacenar, procesar, transmitir y presentar información en cualquier formato con voz, datos, textos e imágenes, para hacer fluir de forma ágil la información y el conocimiento, es una herramienta de gestión de los recursos humanos y un mal uso de la misma puede ser un obstáculo para el desarrollo normal de la compañía. 
En cuanto a los beneficios de una adecuada estrategia de comunicación interna, de acuerdo a Zapata (2013) podemos mencionar: 1) mensajes unificados con la misión, visión y valores, 2) compartir logros haciendo partícipes a los empleados de la buena marcha de la empresa y facilitar la circulación de la información, 3) permite el flujo de información de abajo hacia arriba en la cadena de mando en forma de propuestas y retroalimentación.

Por otro lado, de acuerdo a Maldonado y García (2018), los elementos para mejorar la comunicación interna, son:

- Correo electrónico institucional permite un intercambio rápido de información.

- Boletines internos mensual o semanal en donde se brinde al trabajador noticias de interés, información importante y se fomente el intercambio entre pares.

- Manual del empleado: se le entrega al trabajador la información como la historia de la organización, su organigrama empresarial, su misión, visión y valores.

- Carteleras informativas: se pueden desarrollar por departamento o centralizadas en una coordinación de información, deben estar en lugares muy visibles o de mucho tránsito, en los que pueda ofrecerse información de diverso tipo e incluso convocar a la participación al público interno.

- Circulares: son documentos de interés que circulan, entre departamentos o trabajadores.

- Intranet: son redes computarizadas a las que tienen acceso únicamente los miembros de la organización, pudiendo compartir archivos, tener videoconferencias o enviarse documentos.

- Los videos permiten enviar mensajes combinados con textos e imágenes de entrevistas o mensajes, el $82 \%$ de los usuarios de Internet ven vídeos habitualmente.

- Al mejorar la comunicación en redes sociales la productividad de los empleados aumenta entre un $20 \%$ y un $25 \%$, los empleados comparten información de forma constante, facilitan y hay transparencia, con la posibilidad de que otros usuarios vean y aprovechen ese conocimiento.

- La wiki agiliza el acceso a la información para compartirla o aclarar dudas que otros usuarios habrán aportado sobre determinado tema.

- Con el tablón de anuncios se comunican a los rangos superiores o inferiores de manera visual la información que emite la empresa, pudiendo participar con el buzón de sugerencias.
La comunicación externa se da entre el interior de una organización con gente del exterior con los que hay vinculación como los clientes, competidores 0 proveedores, está regida por la identidad corporativa o distintivos estéticos como logotipos, colores, boletines al público, publicidad, correos electrónicos o marketing en redes sociales, canalizarla se convierte en una necesidad, que aumentará con el tamaño de la organización (Jiménez, 2007).

Comunicación ascendente

La comunicación ascendente se realiza desde abajo hacia arriba en la estructura administrativa de la empresa con la retroalimentación, sirve para dar ideas, sugerencias o proposiciones para quienes toman las decisiones estratégicas, o para hacer solicitudes formales, está representada en organigramas o estructuras organizacionales, la falta de comunicación ascendente puede generar una miopía directiva, tiende a deformarse en la medida y proporción que la información circula por los diferentes niveles de la organización, su objetivo también es estar en conocimiento de lo que sucede, conocer al personal, escuchar sugerencias, mejorar el ambiente de trabajo, propiciar la participación e interés del empleado, obtener información o tomar decisiones (Marketing, XXI).

\section{Comunicación descendente}

La comunicación descendente es la que fluye de un nivel superior a un inferior es decir de un jefe a un subordinado, tiene por objetivos compartir el que, el cómo, el quien, el dónde, el cuándo, el porqué del trabajo transmitiendo noticias o políticas, también el cómo dirigir, instruir, informar, aconsejar y buscar el conocimiento de los subordinados por medio de circulares, boletines, ordenes, instrucciones, reglas, manuales, reglamentos, informes, avisos, comunicaciones y entrevistas, como función de intercambio considera el saber preguntar, escuchar, asesorar y exponer (Fandos, 2003).

Cuando falta la comunicación descendente puede haber un descabezamiento en la dirección ya que la ausencia de mando puede ser incluso peor que el exceso y los mensajes salientes desde la empresa pueden ser discordantes ante la falta de un criterio claramente comunicado, la falta de mensajes desde los mandos superiores desvincula a los empleados de los objetivos de la empresa y eso repercute en su motivación y productividad, y se convierten en un reto para una comunicación efectiva (Hernández, 2015).

Comunicación horizontal

Se da entre pares, o colegas de un mismo equipo, a la misma altura, o entre jefes de distintos departamentos, tiene por objetivo coordinar el trabajo, dar solución a 
problemas, interpretar órdenes en términos inteligibles, informalmente se apoyan entre compañeros de trabajo, esta forma contrarresta actitudes de jefes autoritarios, evita la circulación de rumores, a través de ella se intercambian ideas, puntos de vista, conocimientos, experiencias e inquietudes (Maldonado, 2013).

Comunicación vertical

Es cualquier forma de traspaso de información hacia arriba o hacia abajo dentro de la cadena jerárquica. Ambas, horizontal y vertical, pueden ser comunicación formal o informal. La primera sucede cuando se utilizan los canales formalmente establecidos por la empresa, mientras que la segunda corresponde a la información que circula sin sufrir más rigidez que la que marca la comunicación interpersonal (Salazar \& Guerrero, 2009).

\section{Comunicación circular}

Este tipo de comunicación tiene lugar generalmente entre los miembros de un equipo, cada uno de ellos puede comunicar con los miembros más cercanos. En este escenario

\section{Comunicación free flor}

Cada miembro del grupo puede hablar con todas las otras personas en el grupo.

\section{Comunicación en cadena}

La comunicación en cadena se refiere a la comunicación entre un superior y un subordinado incluyendo a todas las personas que laboran en una organización.

\section{Comunicación invertida}

Comunicación invertida, en esta forma de comunicación, un subordinado se le permite comunicarse con el jefe de su jefe, a una velocidad rápida (Hernández, 2015).

\section{Barreras de las comunicaciones}

La información puede ser rechazada consciente o inconscientemente, las barreras son factores 0 circunstancias que limitan, deforman, obstaculizan o hacen imposible el proceso de la comunicación, por ejemplo los problemas que merman la comunicación son rangos, estados de ánimo, idioma, semántica de las palabras, usuarios, fraudes, uso de la información, tipo o tamaño de letra, sea minúscula o mayúscula con signos de admiración e interrogación, jerarquías, autoridad, expectativas del jefe o subordinado, apreciación de la actividad a desempeñar, falta de incentivos, falta de coordinación fomentado por un sentimiento exagerado de auto importancia, falta de respuesta o la falsa idea de que el silencio es la mejor prueba de que todo está bien (Jiménez, 2007).

El Cuadro 1 presenta características y recomendaciones basadas en Zapata (2013) para minimizar los efectos de los tipos de barreras en la comunicación.

Cuadro 1. Tipos de barreras en la comunicación

\begin{tabular}{|c|c|c|}
\hline $\begin{array}{l}\text { Tipos de } \\
\text { barreras }\end{array}$ & Características & Recomendación \\
\hline Psicológicas & $\begin{array}{l}\text { Se presenta por el } \\
\text { significado distinto de las } \\
\text { palabras entre el emisor y } \\
\text { receptor } \\
\\
\text { Se observan reacciones } \\
\text { emocionales, vergüenza, } \\
\text { enojo, } \\
\text { experiencias, defensa, } \\
\text { conocimientos, estados de } \\
\text { ánimo, factores mentales, } \\
\text { temperamentos, } \\
\text { interpretación bueno o malo } \\
\text { del mensaje que impiden o } \\
\text { bloquean la comprensión o } \\
\text { aceptación de ideas ajenas }\end{array}$ & $\begin{array}{l}\text { - Usar lenguaje simple y } \\
\text { espontáneo } \\
\text { - Confirmar con el receptor los } \\
\text { puntos centrales del } \\
\text { mensaje. } \\
\text { - Tratar de conocer al receptor } \\
\text { - Enviar información adecuada } \\
\text { y a la altura de las } \\
\text { experiencias a } \\
\text { conocimientos del receptor. } \\
\text { - Las experiencias vividas o } \\
\text { expectativas. }\end{array}$ \\
\hline Fisiológicas & $\begin{array}{l}\text { Se presentan por defectos } \\
\text { físicos de las personas que } \\
\text { afectan sus sentidos para } \\
\text { lograr una adecuada } \\
\text { comunicación, } \\
\text { deficiencias como } \\
\text { impedimentos para oír, ver, } \\
\text { hablar. }\end{array}$ & $\begin{array}{l}\text { - Mejorar la visión o audición } \\
\text { de los mensajes. } \\
\text { - Apoyar médicamente al } \\
\text { empleado en cuestión. }\end{array}$ \\
\hline Física & $\begin{array}{l}\text { Son las circunstancias que } \\
\text { se presentan en el medio } \\
\text { ambiente y que impiden una } \\
\text { buena comunicación, como } \\
\text { el ruido, la iluminación, la } \\
\text { distancia y fallas o } \\
\text { deficiencias en los medios } \\
\text { que se utilizan para } \\
\text { transmitir el mensaje } \\
\text { (teléfono, micrófono, fallas } \\
\text { de internet o señal), o mala } \\
\text { acústica del lugar. }\end{array}$ & $\begin{array}{l}\text { - Eliminar el ruido } \\
\text { - Aumentar la claridad y } \\
\text { fortaleza del mensaje. } \\
\text { - La presentación, actitud, o } \\
\text { gesticulares. }\end{array}$ \\
\hline Administrativas & $\begin{array}{l}\text { Se presentan por } \\
\text { deficiencias de la } \\
\text { organización, operación, } \\
\text { planeación, supuestos no } \\
\text { aclarados, distorsiones } \\
\text { semánticas, expresión } \\
\text { deficiente, pérdida de la } \\
\text { transmisión y mala } \\
\text { retención o planeación o } \\
\text { por defectuosa operación } \\
\text { de los sistemas o equipos, } \\
\text { también se presentan por } \\
\text { actitudes del personal, } \\
\text { como ocultar información, } \\
\text { acciones parar pon los jefes } \\
\text { congratularse con la debida } \\
\text { y no dar la ob o } \\
\text { importancia a las órdenes e } \\
\text { instrucciones, para evitar } \\
\text { castigos y muchas otras } \\
\text { causas }\end{array}$ & $\begin{array}{l}\text { - Mejorar la planeación y la } \\
\text { - } \text { organización. } \\
\text { - de problemas técnicas de solución } \\
\text { - Usar retroalimentación } \\
\text { - Dar seguimiento a la } \\
\text { comunicación. } \\
\text { - Usar símbolos, sencillos y } \\
\text { multiplicidad de canales. } \\
\text { - Controlar las emociones } \\
\text { - Controlar la cantidad y } \\
\text { calidad de la información. }\end{array}$ \\
\hline
\end{tabular}

Fuente: Zapata (2013)

\section{Auditoría de comunicación interna}

Con la auditoría de comunicación interna se conocen las debilidades y fortalezas de la organización y constituye el 
paso obligado para la realización de un plan estratégico consistente, permite corregir las disfunciones en la comunicación y las causas que las generan, mejora su aportación a los objetivos finales de la empresa, opinando sobre el porqué de los problemas, sobre cómo deben realizarse las acciones y elaborarse los planes, y cuál es la estrategia correcta a seguir, marca las líneas para establecer el plan estratégico de comunicación que sistematice las comunicaciones de la compañía, optimice los canales y establezca las pautas para que cada integrante de la organización sepa qué comunicar, a quién y por qué medios (Fandos, 2003):

- La calidad de los contenidos de los canales de comunicación y su eficacia.

- La adecuación de las herramientas de comunicación interna a la estrategia de negocio de la organización.

- Las necesidades de información en los distintos niveles de la organización, en calidad y volumen.

- La satisfacción de los empleados y calidad del clima laboral.

- La percepción que tiene de la organización el público interno sobre temas fundamentales y los diferentes públicos que intervienen en la comunicación interna.

A través de la auditoria se realiza una radiografía de cómo es la comunicación interna y acerca de cómo se debe comunicar, revisa las prácticas, comprueba, detecta necesidades informativas y problemas entre los colaboradores, reduce costos, propone procedimientos más eficientes, se corrigen desviaciones observadas, moviliza a directivos, líderes y mandos (emisores y receptores de información) a fin de que sus mensajes sean mejores y hagan posible una comunicación óptima y rentable, si la auditoría se ha realizado anteriormente, para comparar los resultados obtenidos con los de otras auditorías (Maldonado \& García, 2018). Esto tiene un impacto en la gestión diaria y resultados finales de la institución, porque reduce los conflictos, mejora el clima laboral, optimiza los procesos internos ya que satisface las necesidades propias de la empresa y contribuye a alcanzar los objetivos finales de la misma, ayuda a la empresa a difundir su política y su propia identidad y encauza el flujo de información, es una vía para que las personas se sientan más involucradas en sus actuaciones cada día, incrementa la satisfacción de los empleados y su grado de compromiso e implicación con la dirección de la organización, ayuda a la organización a lograr sus metas globales, ya que transmite con velocidad y claridad tanto la política empresarial como los cambios acontecidas en la misma, mejora la comunicación entre los departamentos, empleados y sus funciones (Hernández, 2015).

\section{Identidad}

Como factor relevante en la comunicación es la identidad, que se define como el conjunto de rasgos propios de un individuo o una colectividad que los caracterizan o diferencian de los demás, cuando existe una buena comunicación se genera una mejor identidad e imagen de la empresa (Figura 3) que puede modificar la conducta, mejorar la cultura y clima organizacional, el objetivo es comprometer y mantener enfocados a los empleados con el cumplimiento de los objetivos propuestos a través del trabajo en equipo, buscando la supervivencia institucional (Salazar \& Guerrero, 2009).

Figura 3. Elementos de la imagen institucional

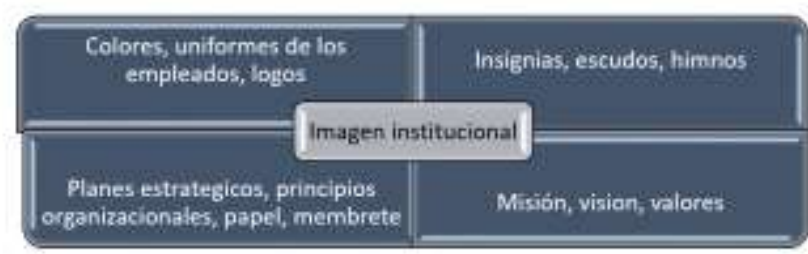

Fuente: Elaboración propia

Una buena comunicación genera un clima organizacional adecuado, mejores condiciones, entornos de trabajo sanos y agradables, hace que la empresa sea más acogedora con empleados contentos, por lo que rendirán más, serán más productivos y el índice de ausentismo baje, los trabajadores demostraran mejores actitudes y aptitudes relacionadas con su carácter, lo deseable en cualquier compañía sería que su personal fuera proactivo (Cuadro 2).

Cuadro 2. Diferencias empleado proactivo y reactivo

\begin{tabular}{|c|c|}
\hline Empleado proactivo & Empleado reactivo. \\
\hline $\begin{array}{l}\text { - } \quad \begin{array}{l}\text { Comprende los objetivos de la } \\
\text { empresa. }\end{array} \\
\text { - } \quad \text { Es una persona enfocada en } \\
\text { conseguir los logros empresariales. } \\
\text { - } \quad \text { Es disciplinado y cumple directrices } \\
\text { establecidas. } \\
\text { - } \quad \text { Se adelanta a los hechos y realiza } \\
\text { buenas propuestas. } \\
\text { - } \quad \text { Es entusiasta y propositivo. } \\
\text { - Tiene buen criterio para actuar en } \\
\text { - } \quad \text { las crisis. } \\
\text { - } \quad \text { Senera confianza. } \\
\text { responsabilidades. } \\
\text { - Es un líder positivo que tiene } \\
\text { credibilidad. }\end{array}$ & 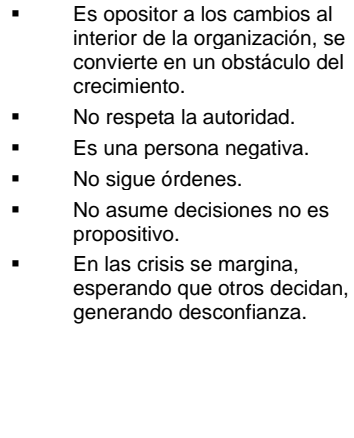 \\
\hline
\end{tabular}

Fuente: Elaboración propia 
Con esta premisa se realiza la entrevista de trabajo, una etapa fundamental en las organizaciones para el éxito de los proyectos que se desarrollen al interior de las mismas y la consecución de los objetivos. Si una entrevista de trabajo no se realiza correctamente se corre el riesgo de contratar malos talentos, los reclutadores son los encargados de realizar esta tarea, que se convierte en el génesis del clima organizacional de la empresa, factor esencial de los resultados (Maldonado, 2013).

\section{Conclusiones}

La comunicación debe ser un medio eficiente de transmitir información, sugerencias, ordenes, capacitación y propiciar un clima agradable que permita la socialización y motivación de los trabajadores por medios personales 0 electrónicos y genere una identidad que despierte el compromiso de los trabajadores que permita a la organización elevar su productividad y desarrollar la innovación en sus trabajadores para permanecer y crecer en el mercado, se deben de evitar tecnicismo en su transmisión, o sobreentender que se dijo con la retroalimentación, debe haber respeto y respaldo hacia todos los integrantes de la organización para que exista confianza y credibilidad en lo que se dice.

No es casualidad que en los niveles bajos se den buenas propuestas para mejorar el trabajo, si no se ofrece a partir de la experiencia y conocimiento generado con las actividades diarias y repetitivas que tienden a mejorar los procesos que se convierte en capital intelectual de las personas, pero que es importante que existan el ambiente y medios para que estos conocimientos puedan ser compartidos.

\section{Referencias}

Fandos (2003). Formación basada en las Tecnologías de la Información y Comunicación: Tesis doctoral. Universitat Rovira I. Virgili.

Hernández (2015). Comunicación formal e informal en las organizaciones. Recuperado de Comunicación formal e informal en las organizaciones • Gestiopolis

Jiménez (2007). La comunicación empresarial en tiempos de crisis. Tesis doctoral. Universitat de Barcelona.

Marketing XXI (2021). La comunicación interna. Centro de Estudios Financieros. Recuperado de https://www.marketing-xxi.com/lacomunicacion-interna-119.htm

Maldonado (2013). Entrevista laboral y selección de personal. Tesis. Universidad Rafael Landívar.

Maldonado \& García (2018). El efecto de las TIC y redes sociales en estudiantes universitarios. Recuperado de El efecto de las TIC y redes sociales en estudiantes universitarios (redalyc.org)

Salazar \& Guerrero (2009). Clima y cultura organizacional: dos componentes esenciales en la productividad laboral. Recuperado de
Clima y cultura organizacional: dos componentes esenciales en la productividad laboral (sld.cu)

Lorente \& Jiménez (2009). La comunicación en salud desde las perspectivas ética, asistencial, docente y gerencial. Recuperado de La comunicación en salud desde las perspectivas ética, asistencial, docente y gerencial (sld.cu)

Zapata (2013). Plan estratégico de comunicación interna. Recuperado de Plan estratégico de comunicación interna: cuáles son sus etapas (talentosreunidos.com) 